Rev. Adm. Saúde (On-line), São Paulo, v. 21, n. 82: e280, jan. - mar. 2021, Epub 24 mar. 2021 http://dx.doi.org/10.23973/ras.82.280

PERSPECTIVAS

\title{
Somos Atenas ou Florença? Covid-19 em contexto histórico
}

Are we Athens or Florence? Covid-19 in historical context

\section{Benjamin R Doolittle ${ }^{1}$}

1. Internal Medicine \& Pediatrics, Yale University, New Haven, Connecticut, EUA

Nós já estivemos aqui antes. Em 430 a.C., uma praga atingiu Atenas, matando $25 \%$ da população. Em 1347 d.C., a peste bubônica atingiu a Europa ocidental por quatro anos, matando $50 \%$ da população. A praga de Atenas levou ao colapso de sua religião, normas culturais e democracia. Em contraste, a peste bubônica acabou levando ao Renascimento, um crescimento da arte, da ciência e do humanismo. Agora que enfrentamos a pandemia global COVID-19, nos tornaremos Atenas ou Florença?

No ano 430 a.C., uma praga se abateu sobre Atenas (1) e Thucydides, o historiador grego, deu um testemunho ocular sobre a doença, em sua obra: "A Guerra do Peloponeso." 


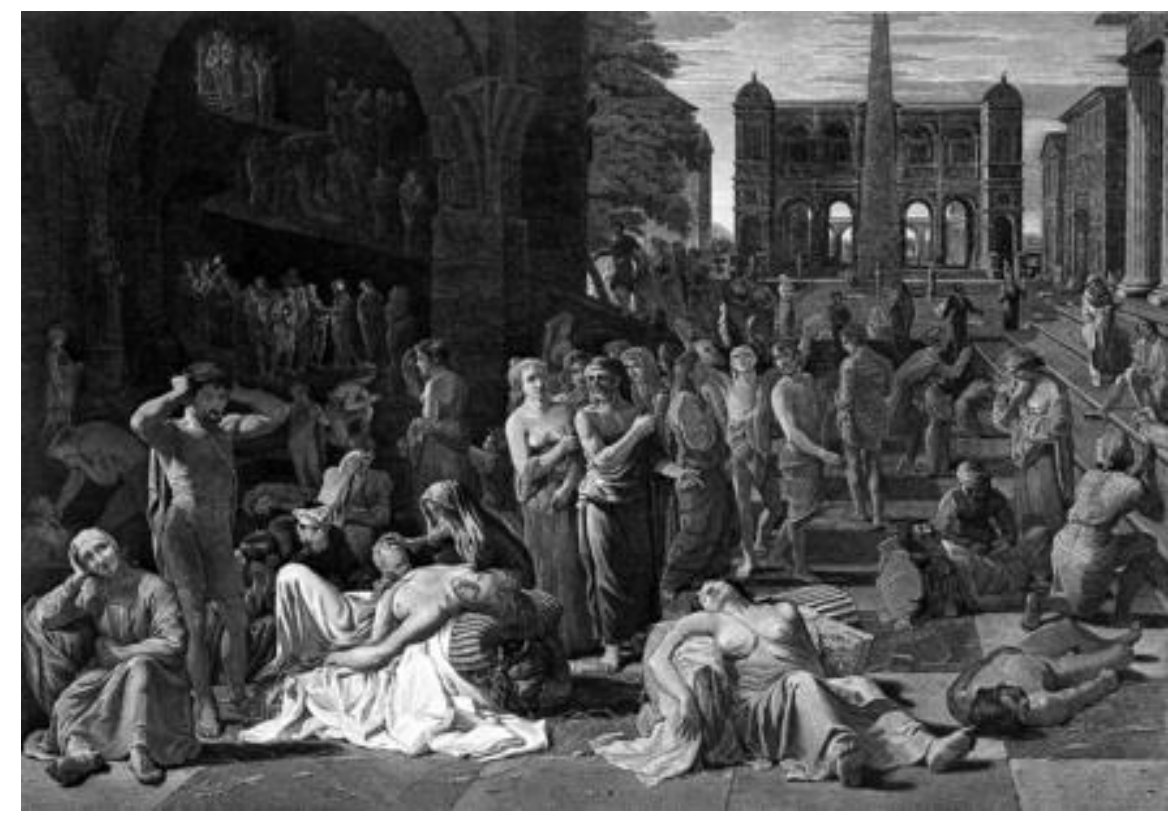

Figura 1. Peste em uma cidade antiga por Michiel Sweerts, comumente considerada a representação da praga de Atenas.

"A doença começou com forte febre na cabeça e vermelhidão e ardor nos olhos; os primeiros sintomas internos foram que a garganta e a língua ficaram sangrentas e o hálito não natural e fedorento. Quando se instalou no coração, convulsionou e produziu todo tipo de evacuação de bile conhecida pelos médicos, acompanhada de grande desconforto. A maioria das vítimas sofria de náuseas vazias, o que induzia a convulsões violentas: elas diminuíam depois disso para alguns sofredores, mas apenas muito mais tarde para outros. A maioria morreu por volta do sétimo ou nono dia" (2).

Os estudiosos têm debatido a etiologia desta epidemia (3). Há evidências convincentes de que a infecção era uma forma de tifo baseada em estudos paleopatológicos de registros dentários, mas outras possibilidades convincentes poderiam ser febre tifoide, peste ou sarampo (3). As cidadesestados de Atenas e Alexandria sofreram. Vinte e cinco por cento da população morreu. $O$ fato teve enormes repercussões. Seu governo democrático entrou em colapso. A devassidão reinou entre os cidadãos. Eles invadiram as casas dos mortos, cometeram atos de violência uns contra os outros e deram as costas às instituições estabelecidas. Sua religião foi dissolvida. "Por que suplicar aos deuses quando todas as petições e sacrifícios ficaram sem resposta?" A praga atingiu, durante a Guerra do Peloponeso, a grande luta entre os autocráticos espartanos e os democratas atenienses. Com uma população dizimada e um moral enfraquecido, os espartanos esmagaram a liga ateniense. Atenas perdeu seu status de superpotência durante séculos (3).

No ano de 1347, um navio do Mar Negro navegou até o porto siciliano de Messina. Havia passageiros clandestinos a bordo: ratos infestados de pulgas carregando Yersinia pestis. Nos anos seguintes, entre $30 \%$ e $50 \%$ da população da Europa Ocidental, morreu de peste bubônica (4). O escritor 
italiano Giovanni Boccaccio escreve em seu célebre Decameron um relato, de primeira mão, sobre a peste em Florença (Figura 2) (5).

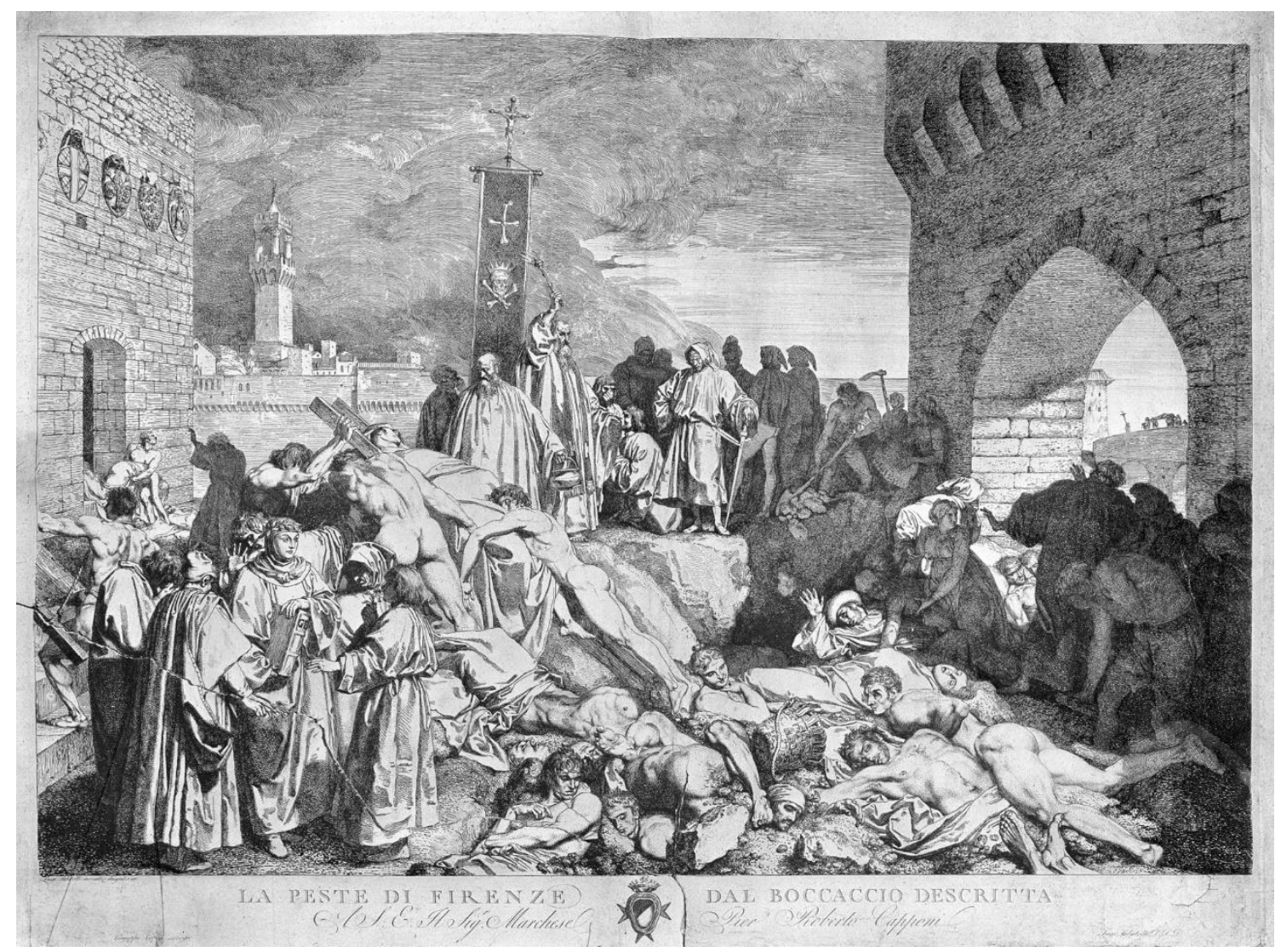

Figura 2. A praga de Florença em 1348, conforme retratada no Decameron de Boccacio, gravada por Luigi Sabatelli.

Começou em homens e mulheres com certos inchaços na virilha ou sob a axila. Eles cresciam até o tamanho aproximado de uma pequena maçã ou de um ovo e eram vulgarmente chamados de tumores. Logo depois disso, os sintomas mudaram e apareceram manchas pretas ou roxas nos braços, nas coxas ou em qualquer outra parte do corpo, às vezes algumas grandes, às vezes muitas pequenas. Essas manchas eram um sinal certo de morte, assim como o tumor original havia sido e ainda permanecia (6).

E, no entanto, a peste bubônica incitou uma releitura completa da sociedade. Os velhos costumes foram destruídos. O declínio da população leva ao colapso da sociedade feudal, ao surgimento de uma classe mercantil independente e a um aumento dos salários reais. As cidades-estados estabilizaram e consolidaram o poder. A economia despertou. Novas ideias surgiram: humanismo e ciência moderna. Michelangelo esculpiu David. Leonardo esboçou sua máquina voadora. A devastação da sociedade criou espaço para o Renascimento (4). 
Nós já estivemos aqui antes. As pandemias são forças poderosas que moldam nossa cultura por gerações e influenciam dramaticamente o resultado dos eventos mundiais. $O$ advento da escravidão na América do Norte pode ser atribuído ao sarampo e à varíola (7). Quando os conquistadores espanhóis invadiram Hispaniola no final do século XV, esses vírus dizimaram $98 \%$ da população local, permitindo que um punhado de conquistadores conquistassem a ilha. Como a população indígena Arawak foi tão reduzida, os conquistadores começaram a importar africanos para trabalhar nas minas e cultivar a cana-deaçúcar, gerando uma tirania de séculos (7). Em 1812, quando Napoleão cruzou o Rio Niemen para a Rússia, seu Grand Armée chegava a quase meio milhão de soldados, o maior que o mundo já tinha visto. Ao se aproximar de Moscou, um surto de disenteria matou 120.000 pessoas, enfraquecendo gravemente seu exército. A única grande batalha contra o exército russo - a Batalha de Borodino - resultou em 30.000 baixas francesas. Enquanto Napoleão fugia, um surto de tifo quase dizimou o resto de seu exército. Cinco meses após a invasão, apenas 10.000 soldados sobreviveram para cruzar de volta a fronteira com a França, a grande maioria morrendo de doenças infecciosas, temperaturas frias e fome (8). Se Napoleão tivesse derrotado a Rússia, o mapa da Europa teria parecido muito diferente. Nossa memória histórica desconsidera o impacto que as pandemias tiveram na formação dos eventos mundiais.

As pandemias revelam o que há de melhor e pior em nós. Durante a pandemia da covid-19, lemos exemplos diários de heroísmo por profissionais de saúde, sacrifício de vizinhos e generosidade de estranhos (9). Durante a peste bubônica, lemos sobre os padres e médicos anônimos que tratavam pacientes, muitas vezes até sua própria morte (4). As pandemias também trazem em nós uma xenofobia e mesquinhez. Em Atenas, os vizinhos roubavam piras funerárias uns dos outros, amontoando seus próprios entes queridos mortos nas pilhas de madeira de seus vizinhos e incendiando-as (10). Durante a peste bubônica, as autoridades culparam aqueles que estavam à margem da sociedade - principalmente os judeus. Em 1349, os magistrados de Estrasburgo culparam os 2.000 judeus pela aflição da peste. Eles os levaram ao cemitério judeu e lhes ofereceram a oportunidade de se converterem. Metade renunciou à sua fé. Metade foi queimada viva (11). A cultura da culpa continua a permear nossa sociedade. Os governos culpam uns aos outros pela disseminação da covid-19. Os especialistas culpam os governos por uma resposta mal coordenada à pandemia. Os governos culpam as grandes farmacêuticas, a mídia e assim por diante.

Como outras pandemias, as rachaduras em nossa sociedade se tornaram maiores e mais aparentes. A covid-19 atingiu desproporcionalmente os pobres e as minorias étnicas. Um governo federal, não informado pela história, subestimou a ameaça e não conseguiu organizar uma resposta nacional robusta. Alguns governos locais mobilizaram recursos que outros não tinham. Uma pesquisa da Johns Hopkins mostrou que a taxa de infecção é três vezes maior em regiões predominantemente negras quando comparadas com as dos brancos, com mortalidade seis vezes maior (12). Um estudo de Harvard entre pacientes com covid-19, em Massachusetts, mostrou que a mortalidade era $40 \%$ maior nas cidades com maior concentração minoritária. A mortalidade foi $14 \%$ maior nas cidades mais populosas em comparação com as menos, e $9 \%$ 
maior naquelas com a maior pobreza (13). Os pobres e marginalizados sofrem mais quando as pandemias acontecem, seja no século V a.C., Atenas, e Florença no século XIV ou Nova York, Arizona ou Texas, no século XXI. Aqui estamos nós, de novo.

Como desta vez será diferente? Como podemos imaginar como serão os serviços de saúde pós-covid? Muito rapidamente, em alguns estados, se implantaram iniciativas de saúde pública que achataram as curvas de incidência e mortalidade. Incorporamos a telessaúde em nossos ambientes ambulatoriais. Reconfiguramos enfermarias em nossos hospitais. Virtualizamos nossos programas educacionais. Nos tornamos muito mais ágeis do que jamais pensamos que seríamos. Que coisas boas vamos guardar? Podemos continuar a inovação para resolver os problemas que tínhamos pré-covid? Para nos tornarmos Florença, ao invés de Atenas, devemos continuar este ímpeto de inovação.

Nós já estivemos aqui antes. Existem forças profundas em jogo em nossa sociedade. $\mathrm{O}$ auto isolamento levou a uma ansiedade cultural, uma desconexão, que precisará de uma visão transcendente para melhorar. As instituições ricas emergiram mais poderosas do que nunca, enquanto os pobres estão ainda mais vulneráveis. As respostas dos governos têm sido lentas, na melhor das hipóteses, com muitos colocando o dinheiro antes da vida humana. Existem questões incômodas para nossa sociedade. É o fim da nossa sociedade ou o início de outro Renascimento? Será que vamos nos lembrar de nossa história? Vamos nos tornar Atenas ou Florença?

\section{REFERÊNCIAS}

1. Sweerts M. Plague in an ancient City.

Available: https://commons.wikimedia.org/wiki/File:Plague in an Ancient C ity LACMA AC1997.10.1 \%281 of 2\%29.jpg [Accessed 23 Jun 2020].

2. Thucydides. The Peloponnesian War. Lattimore S, Translator. Cambridge, UK: Hackett, 1998:98.

3. Cunha BA. The cause of the plague of Athens: plague, typhoid, typhus, smallpox, or measles? Infect Dis Clin North Am 2004; 18:29-43. doi.org/:10.1016/S0891-5520(03)00100-4

4. Getz FM. Black death and the silver lining: meaning, continuity, and revolutionary change in histories of medieval plague. J Hist Biol 1991; 24:265-89.doi.org/:10.1007/BF00209432

5. Sabatelli L. The plague of Florence.

Available: https://commons.wikimedia.org/wiki/File:Boccaccio\%27s \%27The plague of Florence in 1348\%27 Wellcome L0072270.jpg [Accessed 23 Jun 2020]. 
6. Boccaccio G. The Decameron of Giovanni Boccaccio. Aldington R Translator. New York, NY: Dell, 1930: 31.

7. Snowden FM. Epidemics and society: from the black death to the present. New Haven, CT: Yale, 2020: 103.

8. Snowden FM. Epidemics and society: from the black death to the present. New Haven, CT: Yale, 2020: 140-67.

9. Cox CL. 'Healthcare heroes': problems with media focus on heroism from healthcare workers during the COVID-19 pandemic. J Med Ethics 2020; 46:510-3. doi.org/10.1136/medethics-2020-106398

10. Thucydides. The Peloponnesian War. Lattimore S, Translator. Cambridge, UK: Hackett, 1998.

11. Cohn SK. The black death and the burning of Jews. Past Present 2007; 196:3-36. doi.org/10.1093/pastj/gtm005

12. Thebault $\mathrm{R}$, Ba Tran $\mathrm{A}$, Williams $\mathrm{V}$. The coronavirus is infecting and killing black Americans at an alarmingly high rate. Washington post, 2020. Available: https://www.washingtonpost.com/nation/2020/04/07/coronavirusis-infecting-killing-black-americans-an-alarmingly-high-rate-post-analysisshows/ [Accessed 23 Jun 2020].

13. Chen JT, Waterman PD, Krieger N. COVID-19 and the unequal surge in mortality rates in Massachusetts by population. Harvard center for population and development studies 9, 2020.

Available: https://cdn1.sph.harvard.edu/wpcontent/uploads/sites/1266/2020/05/20 jtc pdw nk COVID19 MA-excessmortality text tables figures final 0509 with-cover-1.pdf

\section{Este artigo é tradução livre de:}

Are we Athens or Florence? COVID-19 in historical context Doolittle BR

Family Medicine and Community Health 2021;9:e000811. doi: 10.1136/fmch2020-000811

Recebido: 09 de fevereiro de 2021. Aceito: 24 de março de 2021

Conflito de Interesses: os autores declararam não haver conflito de interesses. 
(C) This is an Open Access article distributed under the terms of the Creative Commons Attribution License, which permits unrestricted use, distribution, and reproduction in any medium, provided the original work is properly cited 